Children Journal of Children and Media and Media

\title{
Past tensions and future possibilities: ARCYP and children's media studies
}

\section{Stuart R. Poyntz, Natalie Coulter \& Geneviève Brisson}

To cite this article: Stuart R. Poyntz, Natalie Coulter \& Geneviève Brisson (2016) Past tensions and future possibilities: ARCYP and children's media studies, Journal of Children and Media, 10:1, 47-53, DOI: $10.1080 / 17482798.2015 .1121887$

To link to this article: https://doi.org/10.1080/17482798.2015.1121887

曲 Published online: 18 Jan 2016.

Submit your article to this journal $₫$

Llll Article views: 408

Q View related articles $\asymp$

View Crossmark data 


\title{
Past tensions and future possibilities: ARCYP and children's media studies
}

\author{
Stuart R. Poyntza, Natalie Coulter ${ }^{\mathrm{b}}$ and Geneviève Brisson ${ }^{\mathrm{c}}$ \\ aschool of Communication, Simon Fraser University, Burnaby, Canada; ${ }^{b}$ Department of Communication \\ Studies, York University, Toronto, Canada; 'Language and Literacy Education, University of British Columbia, \\ Vancouver, Canada
}

\begin{abstract}
The year 2007 marked the beginning. The same year JOCAM was launched, an interdisciplinary group of Canadian scholars formed a scholarly association to address the needs of researchers working with young people's texts and cultures across Canada. In this paper, three members of Association for Research in Cultures of Young People's (ARCYP's) Executive examine current and future tensions within children's media studies by drawing on lessons from ARCYP's opening decade. Both ARCYP and JOCAM emerged during a time of productive intersections between the fields of children's studies and media studies. Here, we draw on ARCYP's history as part of an examination of ongoing lacunae that have arisen as sites of common concern have emerged. These tensions-having to do with notions of textuality and authority, consumption and children's agency and citizenship and power-point to lacunae in the field of children's media studies. ARCYP's history of development is thus taken up as a lens to see the past and imagine the future priorities of our research field.
\end{abstract}

\section{ARTICLE HISTORY}

Received 28 February 2015

Revised 2 September 2015

Accepted 7 September 2015

\section{KEYWORDS}

Children; young people; youth; media; text; culture; ARCYP; children's media studies

The year 2007 marked the beginning. The same year JOCAM was launched, an interdisciplinary group of Canadian scholars formed a scholarly association to address the needs of researchers working with young people's texts and cultures across Canada. Growing out of an "orphan sensibility," a feeling that studies of children and youth occupied a minority or marginal status across the social sciences and humanities, the Association for Research in Cultures of Young People (ARCYP) was born to create an academic home for those working in isolation, to support collaboration and engagement among scholars whose research addresses and redefines our understanding of children's texts and cultures.

ARCYP's history overlaps with the opening decade of the Journal of Children and Media (JOCAM), and many of the reasons for ARCYP's formation are echoed in Dafna Lemish's editorial in the inaugural issue of JOCAM. There, she laments the "scattered nature" of children's media studies and the tendency for scholars to publish in their own disciplinary fields (2007, p. 1). JOCAM's status in scholarly publishing has helped to ameliorate this tendency, and in 
a related manner, ARCYP has helped to provide a home for scholars otherwise orphaned within their own disciplines. In this paper, three members of ARCYP's Executive examine current and future tensions within children's media studies by drawing lessons from ARCYP's opening decade. Both ARCYP and JOCAM emerged during a time of productive intersections between the fields of children's studies and media studies. Where the status of the text is informed by different theoretical and methodological histories in each field, a mutual interest in research about children as active audiences (readers, users and producers of texts) has made for a creative meeting point between the two research areas. The immense and problematic significance of the child as consumer has also enabled a rich collaboration within ARCYP and across children's media studies, foregrounding as it does the new challenges of mediatization, agency, surveillance, labour, participation and commodification that are now shaping the lives of young people. Likewise, transformations in young people's citizenship practices and public media more generally have been key sites of concern that have drawn together children's literature scholars, communication and education researchers, as well as others in ARCYP and children's media studies.

In what follows we draw on ARCYP's history as part of an examination of ongoing tensions and challenges that have arisen as these sites of common concern have emerged. These tensions - having to do with notions of textuality and authority, consumption and children's agency and citizenship and power-point to ongoing lacunae in the field of children's media studies. The tensions evident in ARCYP's history of development might thus be viewed as a lens to see the past and imagine the future of our research field. As three "insiders," connected in various ways to the founding and ongoing development of ARCYP, we draw on anecdotal and systematic knowledge of the association in the paper. Our reading is also informed by interviews with ARCYP's founding president (Mavis Reimer) and an analysis of the ephemera of the association, including the constitution, panel topics at yearly symposia and Executive meeting minutes. These materials and our own recollections and reflections reveal points of convergence with the history of JOCAM, and thus provide a unique lens to examine areas of common concern and points of friction that will inform ARCYP's next decade and the future of children's media studies itself.

\section{It's time to come together}

It is easy to forget how young the field of children's studies is. 1991 is often thought to mark the consolidation and beginning of children's studies as a distinct field of inquiry, separate from the Child Study Movement associated with Stanley Hall (1904) and concerns for children's psychology and development. In contrast, children's studies has long drawn from a more holistic range of disciplines (sociology, anthropology, literature studies, education research, etc.) with the aim of understanding children not as incomplete beings, awaiting their full appearance on the stage of life, but as whole human beings in their own right, with distinct needs, concerns, experiences and possibilities. Children's media studies likewise has long drawn from an interdisciplinary mix of theories and concepts, including youth media studies, which probably has a longer and more widely recognized history associated with the work George Herbert Mead, Robert Park and the Chicago School, Talcott Parson's 1940s research on youth cultures, and the youth cultural studies tradition linked with the names Richard Hoggart, Raymond Williams, Paddy Whannel and Stuart Hall. The Children's Culture Reader (1998) edited by Henry Jenkins has been tagged with 
popularizing the notion of "children's culture." The explosive growth of young people's media culture globally in the waning decades of the twentieth century likely had as much to do as anything else, however, with the increasing interest among scholars, policy-makers and educationalists in children's and youth's media cultures. In this sense, ARCYP, like JOCAM, was overdue on arrival.

ARCYP's inaugural symposium took place in 2008 in Vancouver, Canada and centred on the vexed issue of defining a field and set of terms - "children,"'youth,"'media" and "culture" - to link together scholarship under the umbrella of the association. Ultimately, rather than hashing out precise definitions of these terms, it became more fruitful to foreground the tensions and slippages surrounding the concepts to promote research "across a range of disciplines and to build an understanding of ... scholarship that defines young people, culture, and text, broadly" (ARCYP Constitution). A similar orientation is evident in JOCAM's early issues, where the rich and fertile field of children's media concerns-children's television and parenting, girls' studies, media literacy and media harm debates, media and children's health risks, new media childhoods, news childhoods and comics and graphic novels-are all present. The process through which disciplinary fields (and research associations) come together is always "contingent, uneven and provisional" (Buckingham, 2014, p. 10). Disciplines-and their related research associations and journals - are shaped by the internal dynamics of the field and researchers' own concerns, as well as external pressures from funders and the larger political, technological and cultural character of the times. How these sorts of dynamics have shaped children's media studies is a history yet to be written. Provisionally, however, we contend that three key sites of tension have pervaded the research and publications supported by ARCYP and JOCAM, and these tensions continue to suffuse current and (we suspect) future scholarship about the mediation of young lives.

\section{Textuality and authority}

One of the most challenging lacunae for ARCYP, and perhaps for contemporary children's media studies, has to do with the way textuality and authority are wed together in research settings. At the root of this lacuna is the problem of meaning production; from where does it arise for young people and what concepts and theoretical frames are we to draw on to make sense of this increasingly complex process? Few in children's studies or children's media studies would now begin from the assumption that children and youth are blank slates upon which is written the social, political and cultural meaning in texts. Yet children's texts (visual, aural, literary, graphical, multimodal) continue to be powerful bearers of meaning, ciphers through which literature scholars, among others, diagnose the tenor and possibility of our times and places. In an age, however, when scholars from a range of disciplines (including media studies) have taken seriously the notion that textual meaning is always context dependent, giving authority to textual meaning in and of itself can only ever be a partial kind of cultural analysis. We would also argue that in a time of increasingly flexible digital media, where participation and cross-media production and consumption are among the axes on which cultural meaning is enabled, it is increasingly difficult today to speak of stable forms of textuality. This is not to say that the old cultural studies problem of representation (and textuality) is no longer with us. It is to say that the authority of all kinds of textuality is interwoven with the beingness of the world itself, tied to the people, places and times in which they happen. 
One way-and we suggest not always a helpful way-of interpreting the implications of this statement has been to give attention to young people's voices in children's media studies. This move was apparent in early JOCAM articles (i.e. Cole, Biel, Pai, \& Chand, 2007; Joseph, 2007) and various ARCYP conference papers and panels have trolled this territory. The urgency to document children's and youth's voices also motivated one of the ARCYP's early goals: to encourage partnerships with non-academic organizations, practitioners and young people themselves to give prominence (and authority) to adolescent expression. Ultimately, ARCYP failed to achieve this latter objective, and in a way, our failure is symptomatic of problems that arise when the hierarchies related to textuality and authority are reversed, rather than replaced altogether.

To make sense of how young people's texts and cultures are interwoven with the production of meaning today, it is not enough merely to turn to youth expressions to gain a more authoritative (or authentic) version of young people's being in the world. This move simply substitutes the diagnostic power of one set of texts (child and youth created) for another (adult produced). But, where this move is inadequate on its own, it seems to beg the question: where might children's media studies turn in reconsidering how textuality knits to meaning production in young lives?

One direction that offers exciting possibilities is to give greater attention to the lessons offered by phenomenology. Scannell (2014) mines this territory in his new book, Television and the meaning of live. At root what makes phenomenology interesting in relation to questions of textuality is that texts are not approached merely as social objects, as resources through which the tenor and possibilities of our time might be exhumed. Rather, textuality is taken up as a site of what Ricoeur (1976) calls "surplus meaning," a site wherein the political, economic and cultural inheritances of our lives exist, and a site where the horizons of that which is yet to come can be envisaged. In this way, textuality no longer operates as an authority in and of itself, nor are specific texts read as a cipher for understanding the social nature of young lives. Textuality is interpreted as a form of social presence (and an important one to be sure) happening in time, in real relationships in the midst of a context where young people's lives are unfolding. Textuality is thereby understood in terms of what is being lived, as part of the terms and conditions of youthful being in the world. Here, texts are no longer an authority; their matteringness is calibrated in relation to young lives, as part of the "whereabouts" in which young lives happen (Scannell, 2014).

\section{Consumption and children's agency}

A subtler lacuna for ARCYP has involved questions about the increasing reification of the child as a consumer. Young people are now regularly positioned by the marketplace as sovereign consumers instead of innocents needing protection. Once framed as consumers, however, young people are defined according to the logics of the marketplace. This has increased with an alarming intensity in the neoliberal landscape of global capitalism that has extended its reach virtually everywhere over the past decade. In responding to this intensification, questions about the implications of the increasing reification of the child as consumer have been central concerns in various ARCYP programmes and across a selection of JOCAM publications (i.e. Batada \& Borzekowski, 2008; Buckingham, 2007; Cai \& Zhao, 2010; Gilmore \& Jordan, 2012; Malik \&Wojdynski, 2014; Sigismondi, 2009; Skaar, 2009). Among the issues at stake in this work is a broad sense of concern about the increasing naturalization 
of young people as consumers, including the ways in which consumption has been reified as an innate component of human development and human subjectivity; the logic follows that if children are naturally consumers, then consumption must be natural.

Questions about young people's agency are complicated by these developments. Research in children's studies and children's media studies is increasingly organized around conceptions of young people as actively engaged in the construction of their own social lives. This theme is a recurring narrative in children's studies and has arisen in particular in discussions about young people's play, which is typically addressed as a site of agency where children are understood to engage in processes of meaning making. For our purposes, studies of play have often helped to illustrate the diverse and complex ways children engage with cultural commodities, including how play can challenge the limited and narrow options for young people's agency provided by the marketplace.

Of course in the current moment, transnational corporations are producing a globalized culture of childhood and adolescence that extends into infancy and tends to homogenize young people as gendered and aged consumer subjects, to the exclusion of collective, regional subjectivities. This fulfils the needs of global capitalism as companies can efficiently access global youth markets without having to produce content tailored to specific regions. It also allows for the exclusion of those children and youth who do not fit into homogeneous consumer boxes. Recognizing the agency of young people who actively engage in social processes in their own lives thus confronts globalized constructions of childhood, which dominate much of the transnational mediascape. In many ways, one of the significant contributions of children's media studies has been to help us understand young people in the context of global capitalism, to explore the tensions between the commercial world of young people's cultures and the lived experiences of embodied children and youth. Making sense of these lived experiences is more urgent than ever in a time of big data, consumer surveillance and the ever-increasing intimacy between young people's cultures and marketing. To disclose practices of residual and emergent (Williams, 1977) childhoods may in fact be a primary task for future research in the field. If so, we suggest an equally pressing need is to expose how children's global marketing is migrating and incessantly commodifying what many still conceive of as the sheltered, pre-market worlds of infancy.

\section{Citizenship and power}

A third lacuna ARCYP has encountered in its short history has to do with the question of power and how the meaning of the political is taken up in children's media studies. Questions of citizenship and citizen learning have an important history in children's media studies, not least because of the role and influence of media education in the development of the field. This influence has certainly been uneven; but media literacy has been a major focal point in key national contexts (the UK, Australia, Canada, Scandinavian countries, and more recently, the US) and its concerns have thus helped to shape and give legitimacy to questions of political power and political agency in young people's media studies-against, it should be noted, claims that such concerns are really the purview of older subjects.

Issues of citizenship, political power and their relation to young lives have occupied an important place in children's media studies for other reasons, however. In particular, it is a common refrain today to hear reports across national settings about the apolitical, de-politicized, or anti-political spirit of contemporary children and youth. These descriptions are 
most often intoned in writing about teenagers and those in their 20s, but the intensification of consumer relations in the lives of children and even infants has produced a stream of laments about the marketization, individuation and thus de-politicization of young people more generally. These concerns are no doubt deeply pressing today, and we would be wrong to ignore how the legitimacy and credibility of political concerns has been marginalized, if not eviscerated altogether, in so many instances of contemporary youth texts and culture. Nonetheless, one of the advantages of drawing together researchers from children's studies and media studies has been an eagerness to explore new forms of political expression and mobilization by and for young people.

Panels in ARCYP have addressed how and when young people and their texts and cultures might be thought of as political. Many researchers in children's media studies today would contend that to think through this question, we must begin first, by assuming that power and politics always move in and through the lives of children and youth, and second, by making it clear that young people are both the subjects and objects of the conditions of risk and inequity that are inherent in global consumer cultures. To dig into this situation and bring to the surface how these dynamics are unfolding today, however, it is not enough to imagine politics as only a question of liberal democratic institutionalism - an assumption and weakness of so many laments about the de-politicization of young people. Rather, it requires that we think differently about the nature of the political and the struggle over contemporary power. Our notion of the political cannot be limited to a set of institutions and acts, like voting (although these matter); rather, we suggest it must be understood as a series of frictions and disruptions, spaces of conflict, "competing discourses," stories and performances that make for the "worldliness of the world itself" (Silverstone, 2007, p. 49). Young people-perhaps more than any other demographic - are charting new horizons along these lines, and children's media studies has often been at the forefront of research and work attesting to these developments. If citizenship and power are in fact a lacuna in our field, then, we contend that this may be one area where a kind of dialectic is afoot, one where research in the field is disclosing the emergence of a new kind of politics that promises futures yet to come.

\section{Where do we go from here?}

As the 10-year anniversary of both ARCYP and JOCAM nears, it seems apparent that scholarship about young people's media no longer occupies the marginal status it did a decade ago. ARCYP has established itself in the Canadian academic landscape and continues to grow, and JOCAM is now an internationally recognized journal where scholars will find some of the most interesting and advanced research in the field of children's media studies. Some institutional anchors are in place, then, but we also note that the risk-bearing and risktaking conditions shaping children's and youth's lives are now a constant and pressing feature, impacting young people's identities, health, learning and future job prospects (Appadurai, 2013). Risk is a ubiquitous condition in market-driven, hyperindividualized global societies and if this situation is not altogether new, there is the sense that children's media studies matters more than ever today. Young people continue to be primary inheritors and actors across global media cultures that operate as complex, invasive and powerful care structures across societies. Our task is thus to continue disclosing and contesting these care structures; because they are now, more than ever, the very lineaments through which risk and precarity become naturalized and unspoken conditions of children's and youth's lives. 


\section{Disclosure statement}

No potential conflict of interest was reported by the authors.

\section{Notes on contributors}

Stuart R. Poyntz is an associate professor in the School of Communication at Simon Fraser University and is the president of ARCYP. He is lead editor of the monograph, Phenomenology of Youth Cultures and Globalization (Routledge) and co-author of Media Literacies: A Critical Introduction (Wiley-Blackwell).

Natalie Coulter is an assistant professor at York University in the Department of Communication Studies. She was a founding member of ARCYP, and is currently on the executive. Her book, Tweening the Girl: The Crystallization of the Tween Market, has recently been published by Peter Lang.

Geneviève Brisson is a doctoral candidate in Language and Literacy Education at the University of British Columbia. She has been ARCYP's graduate student representative since 2011. Her research interests include minority language education, identity, multiple and new literacies, and children's and young adult literature.

\section{References}

Appadurai, A. (2013). The future as cultural fact: Essays on the global condition. London: Verso Books.

Batada, A., \& Borzekowski, D. (2008). Snap! Crackle! What? Recognition of cereal advertisements and understanding of commercials' persuasive intent among urban, minority children in the US. Journal of Children and Media, 2, 19-36.

Buckingham, D. (2007). Selling childhood: Children and consumer culture. Journal of Children and Media, 1, 15-24.

Buckingham, D. (2014). Guest editorial: The success and failure of media education. Media Education Research Journal, 4, 5-18.

Cai, X., \& Zhao, X. (2010). Click here, Kids!. Journal of Children and Media, 4, 135-154.

Cole, C. F., Biel, L. S., Pai, S., \& Chand, A. K. (2007). Projecting youth voices: Sisimpur rural filmmaker's project in Bangladesh. Journal of Children and Media, 1, 88-92.

Gilmore, J. S., \& Jordan, A. (2012). Burgers and basketball: Race and stereotypes in food beverage advertising aimed at children in the US. Journal of Children and Media, 6, 317-332.

Hall, G. S. (1904). Adolescence: Its psychology and its relations to physiology, anthropology, sociology, sex, crime, religion and education. New York, NY: D. Appleton.

Jenkins, H. (Ed.). (1998). Children's culture reader. New York, NY: New York University Press.

Joseph, A. (2007). Why children should be seen and heard: An Indian perspective. Journal of Children and Media, 1, 289-293.

Lemish, D. (2007). Launching a new journal: Setting new research agendas. Journal of Children and Media, 1(1), 1-4.

Malik, C., \&Wojdynski, B. W. (2014). Boys earn, girls buy: Depictions of materialism on children's branded entertainment websites. Journal of Children and Media, 8, 404-422.

Ricoeur, P. (1976). Interpretation theory: Discourse and the surplus of meaning. Fort Worth: Texas Christian University.

Scannell, P. (2014). Television and the meaning of 'live': An enquiry into the human situation. Cambridge: Polity Press.

Sigismondi, P. (2009). Global strategies in the children's media market: The Jetix case in Italy. Journal of Children and Media, 3, 152-165.

Silverstone, R. (2007). Media and morality: On the rise of the mediaopolis. Cambridge: Polity Press.

Skaar, H. (2009). Branded selves: How children in Norway relate to marketing on a social network site. Journal of Children and Media, 3, 249-267.

Williams, R. (1977). Marxism and literature. Oxford: Oxford University Press. 